\title{
Antiproliferative 4-(1,2,4-oxadiazol-5-yl)piperidine-1-carboxamides, a new tubulin inhibitor chemotype
}

\author{
Mikhail Krasavin, ${ }^{a}$ Andrey V. Sosnov, ${ }^{b}$ Ruben Karapetian, ${ }^{c}$ Igor Konstantinov, ${ }^{c}$ Olga \\ Soldatkina, ${ }^{c}$ Elena Godovykh, ${ }^{c}$ Fedor Zubkov, ${ }^{d}$ Ruoli Bai, ${ }^{e}$ Ernest Hamel ${ }^{e}$ and Andrei A. \\ $\mathrm{Gakh}^{f, g, h}$
}

${ }^{a}$ Department of Chemistry, St. Petersburg State University, Peterhof 198504, Russia;

${ }^{b}$ ORCHIMED, Institute of Physiologically Active Compounds, Chernogolovka, Moscow Region 142432, Russia; ${ }^{c}$ Chemical Diversity Research Institute, Khimki, Moscow Region 114401, Russia; ${ }^{d}$ Peoples' Friendship University of Russia, Moscow 117198, Russia; ${ }^{e}$ Screening Technologies Branch, Developmental Therapeutics Program, Division of Cancer Treatment and Diagnosis, Frederick National Laboratory for Cancer Research, National Cancer Institute, National Institutes of Health, Frederick, MD 21702, USA; ${ }^{f}$ Oak Ridge National Laboratory, Oak Ridge, TN 37831, USA; ${ }^{g}$ The University of Virginia, Charlottesville, VA 22908, USA; ${ }^{h}$ The Discovery Chemistry Project, Bethesda, MD 20824, USA

\begin{abstract}
We discovered a new chemical class of antiproliferative agents, 4-(1,2,4oxadiazol-5-yl)piperidine-1-carboxamides. SAR-guided optimization of the two distinct terminal fragments yielded a compound with $120 \mathrm{nM}$ potency in an antiproliferative assay. Biological activity profile studies (COMPARE analysis) demonstrated that 4-(1,2,4oxadiazol-5-yl)piperidine-1-carboxamides act as tubulin inhibitors, and this conclusion was confirmed via biochemical assays with pure tubulin and demonstration of increased numbers of mitotic cells following treatment of a leukemia cell line.
\end{abstract}

Keywords: prostate cancer, DU-145, screening, chemotherapeutic agents, rational singlemolecule polypharmacy, tubulin inhibitor 
Prostate cancer represents a major current public health threat and is still an unmet medical need despite recent advances in medical therapeutics. In the USA alone, 240,890 new cases of prostate cancer and 33,720 deaths related to the disease were registered in 2011, ${ }^{1}$ and the statistics remained similarly alarming in $2012 .^{2}$ While the causal relationship between various risk factors and the incidence of prostate cancer is poorly understood, a healthy diet and exercise have been shown to help prevent the disease. ${ }^{3}$ Moreover, a difference in dietary patterns is considered to be the main reason for the significantly lower prostate cancer incidence in Eastern/Southeast Asia as compared with Western countries. ${ }^{4}$ Dietary supplementation with naturally occurring compounds is now contemplated for prostate cancer prevention as a part of a disease-conscious lifestyle. ${ }^{5}$

Men diagnosed with prostate cancer are subject to standard treatments, which include hormone and radiation therapy and surgery. The use of chemotherapy to treat prostate cancer remains largely experimental. ${ }^{6}$ However, the development of targeted small-molecule and antibody-based therapies offers hope for imminent breakthroughs in the treatment of prostate cancer. $^{7,8}$ The current study in the framework of the Discovery Chemistry Project aims to identify novel anticancer compounds with rational single-molecule polypharmacy potential ${ }^{9}$ toward the 'classical' DU-145 human prostate cancer cell line. ${ }^{10}$

We recently reported several novel classes of antiproliferative agents that utilize the A-B-C tricyclic framework, ${ }^{11,12}$ including novel tubulin inhibitors containing the 1,2,4-oxadiazole ring as a single central heterocyclic moiety. ${ }^{13}$ We further hypothesized that additional biomedical benefits can be attained using a dual heterocyclic core by adding a second heterocyclic fragment while retaining the overall linear chain structure of the A-B-C heterocyclic system. One dual heterocyclic core, 4-(1,2,4-oxadiazol-5-yl)piperidine (Figure 1), has been successfully employed for the design of novel bioactive molecules ${ }^{14-16}$ and antiproliferative agents. ${ }^{17,18}$

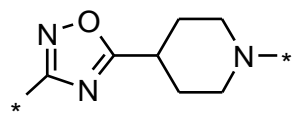

Figure 1. The structure of the 4-(1,2,4-oxadiazol-5-yl)piperidine dual heterocyclic core. 
High-throughput screening of the available collections yielded three closely related 4-(1,2,4oxadiazol-5-yl)piperidine carboxamides (1-3) that inhibited the proliferation of DU-145 cells in a dose-dependent manner, with $\mathrm{GI}_{50}$ values in low micromolar range (Figure 2). Other 4(1,2,4-oxadiazol-5-yl)piperidine derivatives, $N$-acyl, $N$-alkyl or $N$-sulfonyl (>100 compounds in total), did not show detectable activity at a $2 \mu \mathrm{M}$ concentration. This preliminary research indicated that the 1-carboxamide fragment might be an essential part of this newly discovered pharmacophore.

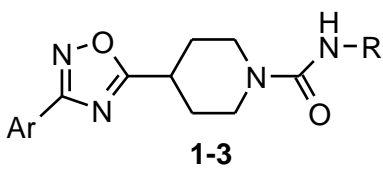

$\begin{array}{llll}1 \mathrm{Ar}=4-\mathrm{ClC}_{6} \mathrm{H}_{4} & \mathrm{R}=\left(2-\mathrm{C}_{4} \mathrm{H}_{3} \mathrm{O}\right) \mathrm{CH}_{2} & \mathrm{GI}_{50}=2.7 \mu \mathrm{M} \\ 2 \mathrm{Ar}=4-\mathrm{MeC}_{6} \mathrm{H}_{4} & \mathrm{R}=3-\mathrm{MeOC}_{6} \mathrm{H}_{4} & \mathrm{GI}_{50}=4.5 \mu \mathrm{M} \\ 3 \mathrm{Ar}=4-\mathrm{FC}_{6} \mathrm{H}_{4} & \mathrm{R}=\left(2-\mathrm{C}_{4} \mathrm{H}_{3} \mathrm{O}\right) \mathrm{CH}_{2} & \mathrm{GI}_{50}=3.3 \mu \mathrm{M}\end{array}$

Figure 2. The structures and $\mathrm{GI}_{50}$ data (DU145 cell line) of the hit compounds (1-3).

Given the presence in the core of compounds 1-3 of two distinct elements, the 1,2,4oxadiazol ring and the carboxamide residue, we performed a SAR investigation around these two motifs independently. Our aim was to identify the terminal substituents that would improve antiproliferative activity. We reasoned that subsequently combining the two independently optimized terminal aromatic substituents within the same molecule might have an additive effect and result in even more potent compounds.

Taking into account our previous success with monofluorinated aromatic substituents, ${ }^{13,19}$ we initially prepared the 4-fluorophenyl substituted compound 4 (Scheme 1) as a starting point of SAR optimization. The first intermediate, amidoxime 5, was synthesized from 4fluorobenzonitrile via the standard reaction with hydroxylamine. ${ }^{20}$ The next intermediate, Boc-protected 4-[3-(p-fluoporphenyl)-1,2,4-oxadiazol-5-yl]piperidine 6, was prepared by one-pot TBTU mediated acylation/heterocyclization. ${ }^{21,22}$ Subsequent Boc group removal provided the desired amine 4 . This known compound ${ }^{23}$ served as a starting material for the preparation of an array of tri- and tetrasubstituted ureas 8a-t via a direct reaction with isocyanates $(\operatorname{Method} A)$. An alternative method $(\operatorname{Method} B)$ involved the preparation of the carbamoyl chloride 7 (Scheme 1). ${ }^{24}$ 


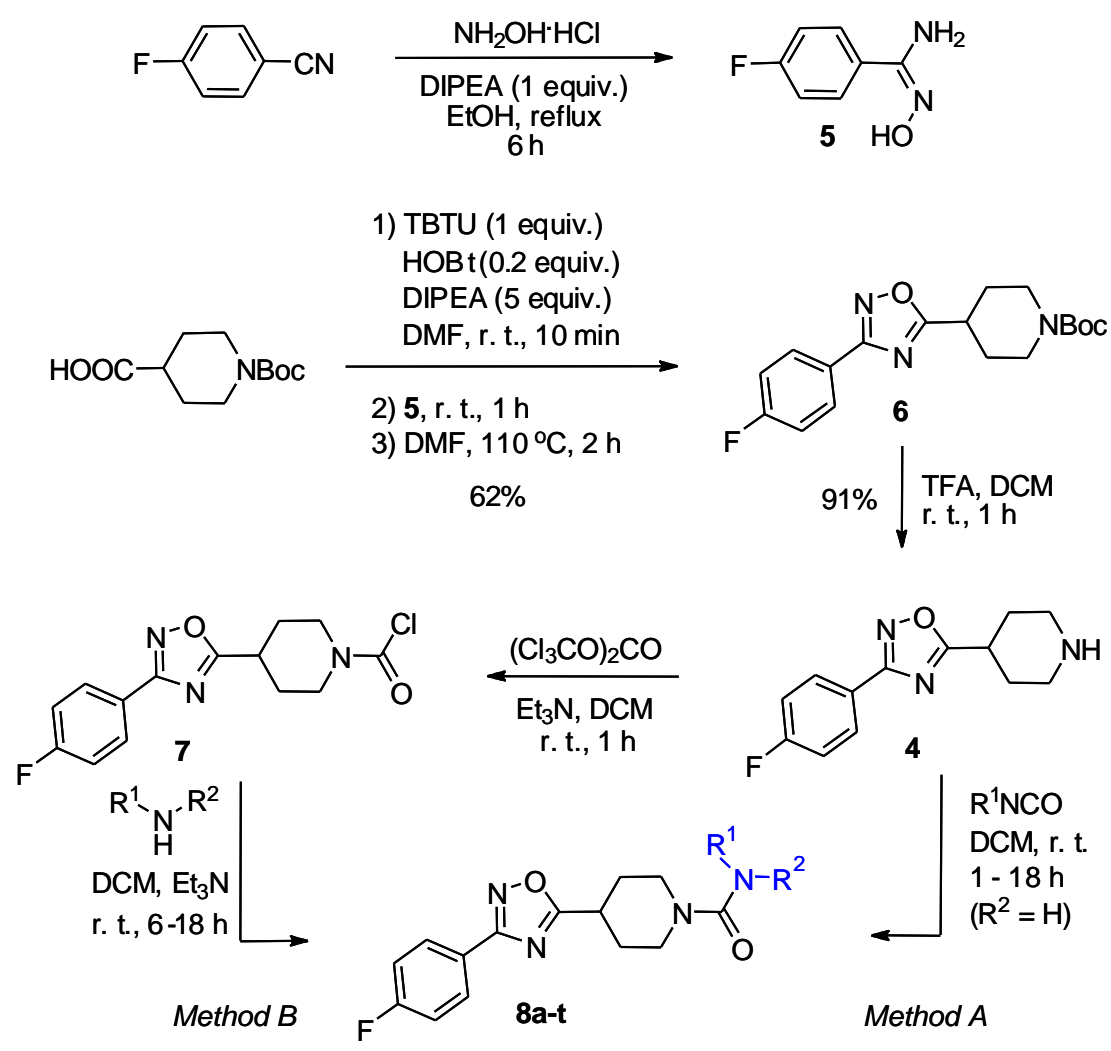

Scheme 1. Synthesis of $p$-fluoporphenyl 4-(1,2,4-oxadiazol-5-yl)piperidine-1carboxamides (8a-t); TBTU - O-(benzotriazol-1-yl)- $N, N, N^{\prime}, N^{\prime}$-tetramethyluronium tetrafluoroborate, $\mathrm{HOBt}$ - 1-hydroxybenzotriazole, DIPEA - N,N-diisopropylethylamine.

An assessment of the antiproliferative activity of the newly synthesized carboxamides 8a-t (Table 1) led to several important SAR generalizations. A mono-substituted carboxamide moiety was found to be essential for antiproliferative activity: exhaustive substitution of the carboxamide nitrogen atom led to markedly lower $(\mathbf{8 a}, \mathbf{8 j})$ or a complete loss $(\mathbf{8 i}, \mathbf{8 1 - 8 \mathbf { n }})$ of activity. The presence of an aromatic or heteroaromatic ring also appeared to be essential, since no activity was detected in the compounds containing aliphatic substituents $(\mathbf{8 b}, \mathbf{8 e}, \mathbf{8 k}$, 8q-s). Benzylic-type groups were obviously favored (8c-d, 8g-h, 8o, 8t), while replacing them with phenethyl-type groups $(\mathbf{8 f}, \mathbf{8 p})$ appeared to lower antiproliferative activity. 
Table 1. Chemical yields of p-fluoporphenyl 4-(1,2,4-oxadiazol-5-yl)piperidine-1carboxamides (8) and their antiproliferative activities against DU-145 cells.

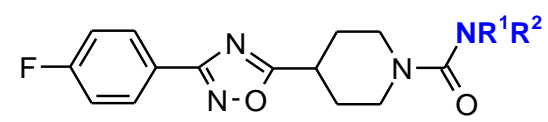

\begin{tabular}{|c|c|c|c|c|}
\hline Compound & $\mathrm{NR}^{1} \mathrm{R}^{2}$ & $\begin{array}{l}\text { Synthetic } \\
\text { route }^{a}\end{array}$ & Yield, \% & $\mathrm{GI}_{50}(\mu \mathrm{M})^{b}$ \\
\hline $\mathbf{8 a}$ & & B & 62 & $17.0 \pm 1.1$ \\
\hline $8 b$ & & A & 88 & Inactive \\
\hline $8 c$ & & B & 51 & $1.7 \pm 0.3$ \\
\hline $8 d$ & & A & 86 & $2.8 \pm 0.4$ \\
\hline $8 e$ & $\mathrm{MeOC}$ & A & 93 & Inactive \\
\hline $8 f$ & & A & 92 & $13.6 \pm 0.6$ \\
\hline $8 g$ & & B & 71 & $0.65 \pm 0.08$ \\
\hline $8 h$ & & B & 64 & $1.1 \pm 0.2$ \\
\hline $8 \mathbf{i}$ & & B & 48 & Inactive \\
\hline $8 \mathbf{j}$ & & B & 55 & $21.0 \pm 0.9$ \\
\hline $8 \mathbf{k}$ & & B & 39 & Inactive \\
\hline 81 & & B & 44 & Inactive \\
\hline $8 m$ & & B & 63 & Inactive \\
\hline $8 n$ & & B & 42 & Inactive \\
\hline 80 & & B & 38 & $0.94 \pm 0.05$ \\
\hline $8 p$ & & B & 29 & $9.8 \pm 0.5$ \\
\hline $8 q$ & & A & 95 & Inactive \\
\hline $8 r$ & & A & 86 & Inactive \\
\hline $8 s$ & & A & 79 & Inactive \\
\hline $8 t$ & & B & 54 & $1.3 \pm 0.2$ \\
\hline
\end{tabular}

${ }^{a}$ Method A - via direct condensation of $\mathbf{4}$ with isocyanates; Method B - via carbamoyl chloride 7.

${ }^{b}$ The data shown are the means of three experiments \pm standard deviation. Inactive -compounds showing $<20 \%$ DU-145 growth inhibition at $50 \mu \mathrm{M}$. 
In parallel with the carboxamide array, a series of 3-substituted 1,2,4-oxadiazoles was prepared by condensing $N$-(benzylcarbamoyl)isonipecotic acid 9 with readily available amidoximes 10a-m using the TBTU-mediated acylation/heterocyclization protocol (Scheme 2). ${ }^{21}$ The starting compound, $N$-(benzylcarbamoyl)isonipecotic acid $\mathbf{9}$, was conveniently prepared via a reaction of ethyl piperidine-4-carboxylate with benzyl isocyanate followed by an ester hydrolysis.

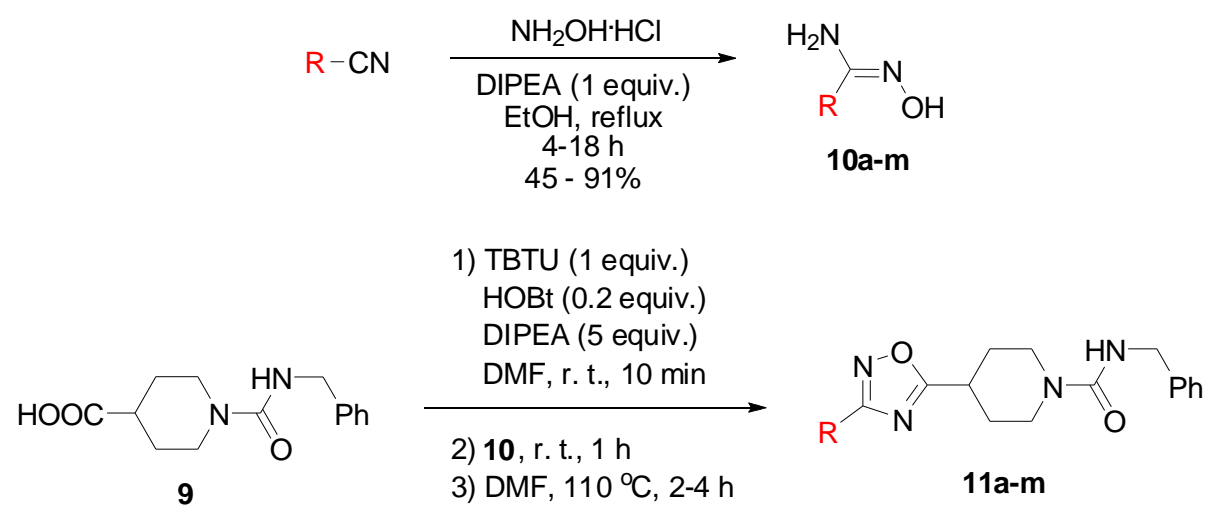

Scheme 2. Synthesis of $N$-benzyl 4-(1,2,4-oxadiazol-5-yl)piperidine-1-carboxamides (11am).

Evaluation of the antiproliferative potency of the resulting 1,2,4-oxazoles 11a-m (Table 2) revealed the importance of additional aromatic groups in this region of the molecule and established the beneficial effect of a flexible linker between the 1,2,4-oxadiazole moiety and an aromatic substituent, as exemplified by compounds $\mathbf{1 1 b}$ and $\mathbf{1 1 d}$. 
Table 2. Chemical yields of $N$-benzyl 4-(1,2,4-oxadiazol-5-yl)piperidine-1-carboxamides (11) and their antiproliferative activities against DU-145 cells.

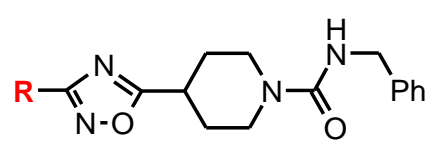

\begin{tabular}{|c|c|c|c|}
\hline Compound & $\mathrm{R}$ & Yield, \% & $\mathrm{GI}_{50}(\mu \mathrm{M})^{a}$ \\
\hline $11 a$ & & 44 & $1.6 \pm 0.2$ \\
\hline $11 b$ & $\mathrm{Bn}$ & 68 & $0.76 \pm 0.09$ \\
\hline 11c & $\mathrm{Ph}$ & 67 & $1.9 \pm 0.4$ \\
\hline 11d & & 58 & $0.52 \pm 0.05$ \\
\hline $11 \mathrm{e}$ & & 32 & $11.2 \pm 1.1$ \\
\hline $11 f$ & & 45 & $8.6 \pm 0.4$ \\
\hline $11 g$ & & 51 & $12.3 \pm 0.7$ \\
\hline $11 \mathrm{~h}$ & & 62 & $1.2 \pm 0.05$ \\
\hline $11 \mathrm{i}$ & & 73 & Inactive \\
\hline $11 \mathrm{j}$ & $\mathrm{Me}$ & 46 & Inactive \\
\hline $11 k$ & & 38 & $9.3 \pm 0.4$ \\
\hline 111 & & 67 & $2.9 \pm 0.2$ \\
\hline $11 \mathrm{~m}$ & & 64 & $4.4 \pm 0.4$ \\
\hline
\end{tabular}

${ }^{a}$ The data shown are the means of three experiments \pm standard deviation. Inactive compounds showing $<20 \%$ DU-145 growth inhibition at $50 \mu \mathrm{M}$.

From the initial orthogonal SAR survey of the 4-(1,2,4-oxadiazol-5-yl)piperidine-1carboxamides 8a-t and 11a-m, we identified two sets of terminal substituents that appeared to have a beneficial effect on the antiproliferative potency of compounds having $\mathrm{GI}_{50}$ values in the submicromolar range $(\mathbf{8 g}, \mathbf{8 o}, \mathbf{1 1 b}, \mathbf{1 1 d})$. We expected that combining these favorable substituents in a 'crossover' set of compounds would have an additive effect on the potency of the resulting compounds. 
'Crossover' compounds 12a-d were subsequently synthesized using methods similar to those presented in Schemes 1 and 2, and the new compounds were then tested for antiproliferative activity against DU-145 cells (Table 3). An additive effect of combining the best terminal fragments was achieved only with compound 12a, the most active compound in the series.

Table 3. $\mathrm{GI}_{50}$ data (DU-145 cells) and structures of the SAR-merging 'crossover' compounds 12a-d.

\begin{tabular}{|c|c|c|}
\hline Compound & $\mathrm{R}^{1}$ & $\mathrm{GI}_{50}, \mu \mathrm{M}^{a}$ \\
\hline $12 \mathrm{a}$ & $\mathrm{Bn}$ & $0.12 \pm 0.03$ \\
\hline $12 b$ & $\mathrm{Bn}$ & $0.95 \pm 0.12$ \\
\hline $12 c$ & $\mathrm{PhOCH}_{2}$ & $1.7 \pm 0.3$ \\
\hline $12 d$ & $\mathrm{PhOCH}_{2}$ & $2.8 \pm 0.2$ \\
\hline
\end{tabular}

${ }^{a}$ The data shown are the means of three experiments \pm standard deviation.

We were also interested in seeing if the geometry of the piperidine moiety could be altered to improve potency. It appeared, however, that the 1,4-piperidine linker was the best, because activity was drastically reduced (compound 15) or completely eliminated (compounds 13, 14 and 16) for linkers with nonlinear geometry (Figure 3). Compounds 13-16 were synthesized similarly to 12a using 2(3)-piperidine and 2(3)-pyrrolidine carboxylate precursors in lieu of the piperidine-4-carboxylate precursor. 


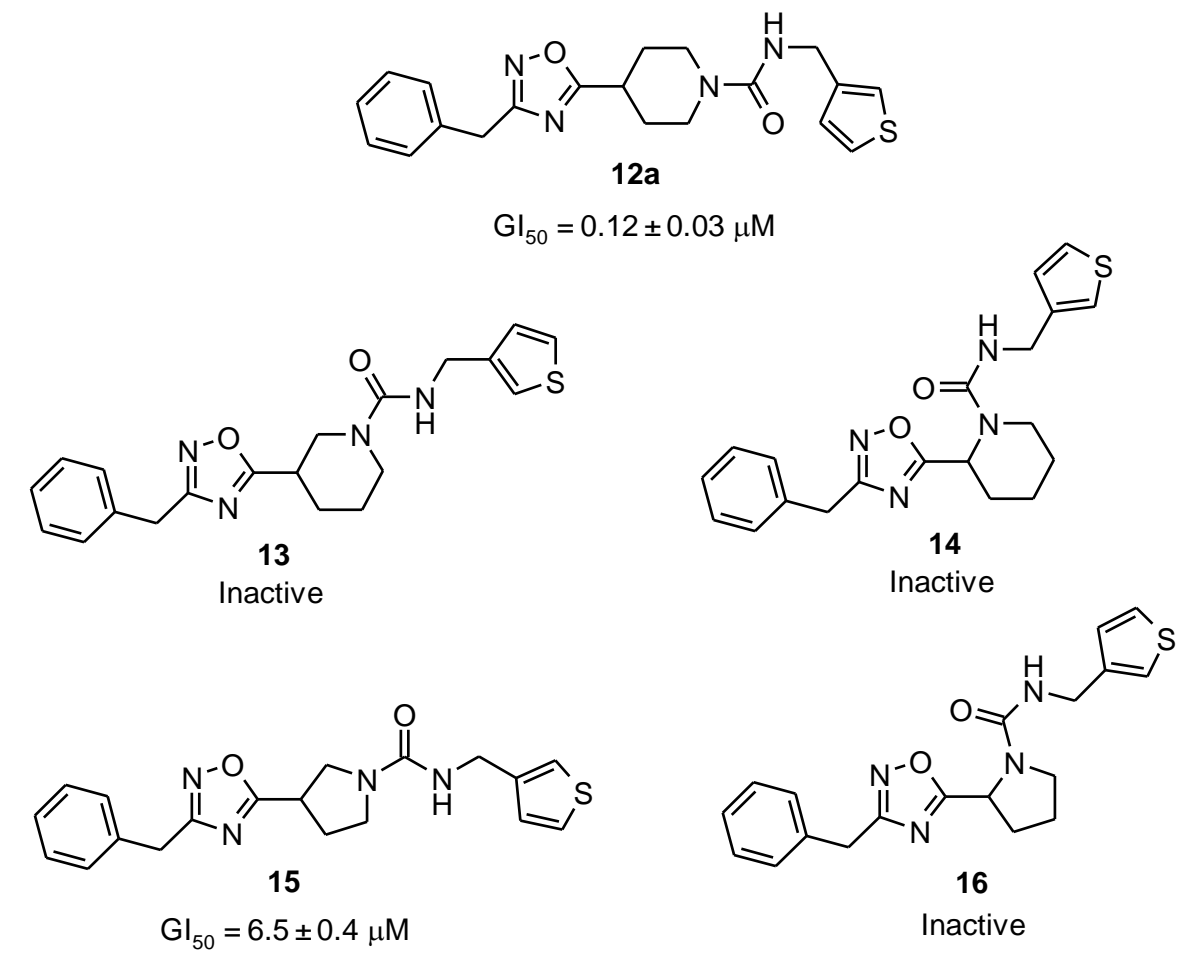

Figure 3. Evaluation of alternative linkers ( $\mathrm{GI}_{50}$ data - DU-145 cells).

Good correlations were observed between some 4-(1,2,4-oxadiazol-5-yl)piperidine-1carboxamides and antiproliferative diaryl 5-amino-1,2,4-oxadiazoles ${ }^{13,25}$ in the 60 -cell line screening tests performed at the National Cancer Institute and analyzed by online COMPARE $^{26}$ software tools (see Supporting Information). These diaryl 5-amino-1,2,4oxadiazoles were recently identified as tubulin inhibitors with polypharmacy potential. ${ }^{13}$

Subsequent direct biochemical experiments confirmed that all tested 4-(1,2,4-oxadiazol-5yl)piperidine-1-carboxamides have antitubulin activity (see Table 4), but display somewhat different features. For example, hit compound $\mathbf{2}$ had reasonable tubulin inhibitor potential $\left(\mathrm{IC}_{50}=3.0 \pm 0.1 \mu \mathrm{M}\right)$. At the same time, 2 elicited a substantially weaker inhibition of colchicine binding $(5.7 \pm 3 \%$ at $1 \mu \mathrm{M}, 8.2 \pm 3 \%$ at $5 \mu \mathrm{M}$, and $19 \pm 0.5 \%$ at $50 \mu \mathrm{M})$ compared to other known tubulin inhibitors, such as diaryl 5-amino-1,2,4-oxadiazoles. ${ }^{13}$ This behavior is unusual but not exceptional ${ }^{27,28}$ among structurally related compounds and warrants further investigation. 
Table 4. Inhibition of tubulin assembly activity $\left(\mathrm{IC}_{50}\right)$ of some 4-(1,2,4-oxadiazol-5yl)piperidine-1-carboxamides.

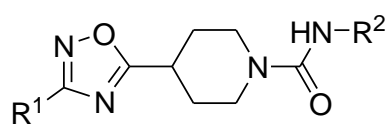

\begin{tabular}{|c|c|c|c|}
\hline Compound & $\mathrm{R}^{1}$ & $\mathrm{R}^{2}$ & $\mathrm{IC}_{50}, \mu \mathrm{M} \pm \mathrm{SD}$ \\
\hline 1 & $4-\mathrm{ClC}_{6} \mathrm{H}_{4}$ & & $2.0 \pm 0.08$ \\
\hline $1 \mathbf{a}$ & 4- $\mathrm{MeC}_{6} \mathrm{H}_{4}$ & & $2.3 \pm 0.2$ \\
\hline 2 & 4- $\mathrm{MeC}_{6} \mathrm{H}_{4}$ & $3-\mathrm{MeOC}_{6} \mathrm{H}_{4}$ & $3.0 \pm 0.1$ \\
\hline $2 \mathbf{a}$ & $4-\mathrm{ClC}_{6} \mathrm{H}_{4}$ & $3-\mathrm{MeOC}_{6} \mathrm{H}_{4}$ & $5.3 \pm 0.5$ \\
\hline 8d & $4-\mathrm{FC}_{6} \mathrm{H}_{4}$ & $\mathrm{Bn}$ & $1.6 \pm 0.1$ \\
\hline $11 a$ & $4-\mathrm{MeC}_{6} \mathrm{H}_{4}$ & $\mathrm{Bn}$ & $1.1 \pm 0.02$ \\
\hline $11 \mathrm{c}$ & $\mathrm{Ph}$ & $\mathrm{Bn}$ & $1.8 \pm 0.1$ \\
\hline $11 k$ & $2-\mathrm{ClC}_{6} \mathrm{H}_{4}$ & $\mathrm{Bn}$ & $2.6 \pm 0.2$ \\
\hline
\end{tabular}

Finally, to verify further the antitubulin mechanism of action, we examined whether selected compounds (8d, 11a, and 11c) would cause mitotic arrest in K562 human leukemia cells. We verified that these three compounds inhibited the growth of these cells $\left(\mathrm{IC}_{50}\right.$ values were $1.2 \pm 0.4,0.55 \pm 0.05,1.5 \pm 0.7 \mu \mathrm{M}$, respectively), and their effects on the mitotic index were examined with the compounds at $5.0 \mu \mathrm{M}$. The mitotic indices for the three compounds were, respectively $72 \pm 20 \%, 83 \pm 7 \%$, and $75 \pm 2 \%$. As a positive control, we used the well described antitubulin, antimitotic agent combretastatin $\mathrm{A}-4^{29,30}$ at $100 \mathrm{nM}(82 \pm 5 \%)$, while without compound the mitotic index was $2 \pm 1 \%$.

While apparently conclusive, these mitotic and tubulin inhibition studies cannot completely rule out the possibility of other targets for 4-(1,2,4-oxadiazol-5-yl)piperidine-1carboxamides. An example of a novel tubulin inhibitor chemotype with dual ligand features was reported recently. ${ }^{31,32}$ In this particular case, the ligand binds to tubulin at the colchicine site inducing a strong antiproliferative action that masks weaker growth inhibition effects caused by heat shock protein 27 (Hsp27) binding. ${ }^{31}$ Small structural variations of the lead compound allow target-specific ligand tuning. ${ }^{32}$ 
In conclusion, we have identified 4-(1,2,4-oxadiazol-5-yl)piperidine-1-carboxamides as a novel class of tubulin inhibitors that have antiproliferative activity in the DU-145 prostate cancer cell line. A two-vector SAR optimization improved the potency of the compounds more than tenfold. The most active compound, 12a $\left(\mathrm{GI}_{50}=120 \mathrm{nM}\right)$, can serve as a new lead for the development of chemotherapeutic agents against prostate cancer.

\section{Acknowledgement}

This paper is a contribution from the Discovery Chemistry Project funded in part by the U.S. Department of Energy in collaboration with the National Cancer Institute. Oak Ridge National Laboratory is managed and operated by UT-Battelle, LLC, under contract DEAC05-00OR22725 for the U.S. Department of Energy.

\section{References}

1. American Cancer Society Cancer Facts \& Figures 20112011.

2. American Cancer Society Cancer Facts \& Figures 20122012.

3. Wilson, K. M.; Giovannucci, E. L.; Mucci, L. A. Asian J. Androl. 2012, 14, 365.

4. Messina, M.; Nagata, C.; Wu, A. H. Nutr. Cancer 2006, 55, 1.

5. Özten-Kandas, N.; Bosland, M. C. J. Carcinog. 2011, 10, 27.

6. $\quad$ Singh, P.; Yam, M.; Russell, P. J.; Khatri, A. Cancer Lett. 2010, 293, 1.

7. Ezzell, E. E.; Chang, K. S.; George, B. J. Curr. Oncol. Rep. 2013, 15, 239.

8. Elsasser-Beile, U.; Buhler, P.; Wolf, P. Curr. Drug Targets 2009, 10, 118.

9. M. O’Boyle, N.; J. Meegan, M. Curr. Med. Chem. 2011, 18, 4722.

10. Alimirah, F.; Chen, J.; Basrawala, Z.; Xin, H.; Choubey, D. FEBS Lett. 2006, 580, 2294.

11. Krasavin, M.; Karapetian, R.; Konstantinov, I.; Gezentsvey, Y.; Bukhryakov, K.; Godovykh, E.; Soldatkina, O.; Lavrovsky, Y.; Sosnov, A. V.; Gakh, A. A. Arch. Pharm. 2009, 342, 420.

12. Vovk, M. V.; Pinchuk, O. M.; Tolmachov, A. O.; Gakh, A. A. Molecules 2010, 15, 997.

13. Gakh, A. A.; Sosnov, A. V.; Krasavin, M.; Nguyen, T. L.; Hamel, E. Bioorg. Med. Chem. Lett. 2013, 23, 1262.

14. Ontoria, J. M.; Bufi, L. L.; Torrisi, C.; Bresciani, A.; Giomini, C.; Rowley, M.; Serafini, S.; Bin, H.; Hao, W.; Steinkühler, C.; Jones, P. Bioorg. Med. Chem. Lett. 2011, 21, 5274. 
15. Muraglia, E.; Ontoria, J. M.; Branca, D.; Dessole, G.; Bresciani, A.; Fonsi, M.; Giuliano, C.; Llauger Bufi, L.; Monteagudo, E.; Palumbi, M. C.; Torrisi, C.; Rowley, M.; Steinkühler, C.; Jones, P. Bioorg. Med. Chem. Lett. 2011, 21, 5283.

16. Shen, H. C.; Ding, F.-X.; Wang, S.; Deng, Q.; Zhang, X.; Chen, Y.; Zhou, G.; Xu, S.; Chen, H.; Tong, X.; Tong, V.; Mitra, K.; Kumar, S.; Tsai, C.; Stevenson, A. S.; Pai, L.Y.; Alonso-Galicia, M.; Chen, X.; Soisson, S. M.; Roy, S.; Zhang, B.; Tata, J. R.; Berger, J. P.; Colletti, S. L. J. Med. Chem. 2009, 52, 5009.

17. Kumar, D.; Patel, G.; Johnson, E. O.; Shah, K. Bioorg. Med. Chem. Lett. 2009, 19, 2739.

18. Kumar, D.; Patel, G.; Chavers, A. K.; Chang, K.-H.; Shah, K. Eur. J. Med. Chem. 2011, $46,3085$.

19. Gakh, A. A.; Burnett, M. N. J. Fluorine Chem. 2011, 132, 88.

20. Burns, A. R.; Kerr, J. H.; Kerr, W. J.; Passmore, J.; Paterson, L. C.; Watson, A. J. B. Org. Biomol. Chem. 2010, 8, 2777.

21. Poulain, R. F.; Tartar, A. L.; Déprez, B. P. Tetrahedron Lett. 2001, 42, 1495.

22. Kiseleva, V. V.; Gakh, A. A.; Fainzil'berg, A. A. Russ. Chem. Bull. 1990, 39, 1888.

23. Flipo, M.; Desroses, M.; Lecat-Guillet, N.; Villemagne, B.; Blondiaux, N.; Leroux, F.; Piveteau, C.; Mathys, V.; Flament, M.-P.; Siepmann, J.; Villeret, V.; Wohlkönig, A.; Wintjens, R.; Soror, S. H.; Christophe, T.; Jeon, H. K.; Locht, C.; Brodin, P.; Déprez, B.; Baulard, A. R.; Willand, N. J. Med. Chem. 2012, 55, 68.

24. Arkin, M.; Mcdowell, R.; Oslob, J.; Raimundo, B.; Waal, N.; Yu, C. Small-Molecule Inhibitors of Interleukin-2 2003, PCT Int. Appl. WO 2003051797.

25. Krasavin, M.; Rufanov, K. A.; Sosnov, A. V.; Karapetian, R.; Godovykh, E.; Soldatkina, O.; Lavrovsky, Y.; Gakh, A. A. Chem. Cent. J. 2010, 4, 4.

26. Zaharevitz, D. W.; Holbeck, S. L.; Bowerman, C.; Svetlik, P. A. J. Mol. Graphics Modell. 2002, 20, 297.

27. Verdier-Pinard, P.; Lai, J.-Y.; Yoo, H.-D.; Yu, J.; Marquez, B.; Nagle, D. G.; Nambu, M.; White, J. D.; Falck, J. R.; Gerwick, W. H.; Day, B. W.; Hamel, E. Mol. Pharmacol. 1998, 53, 62.

28. La Regina, G.; Sarkar, T.; Bai, R.; Edler, M. C.; Saletti, R.; Coluccia, A.; Piscitelli, F.; Minelli, L.; Gatti, V.; Mazzoccoli, C.; Palermo, V.; Mazzoni, C.; Falcone, C.; Scovassi, A. I.; Giansanti, V.; Campiglia, P.; Porta, A.; Maresca, B.; Hamel, E.; Brancale, A.; Novellino, E.; Silvestri, R. J. Med. Chem. 2009, 52, 7512.

29. Lin, C. M.; Singh, S. B.; Chu, P. S.; Dempcy, R. O.; Schmidt, J. M.; Pettit, G. R.; Hamel, E. Mol. Pharmacol. 1988, 34, 200.

30. Lin, C. M.; Ho, H. H.; Pettit, G. R.; Hamel, E. Biochemistry 1989, 28, 6984.

31. Yi, X.; Zhong, B.; Smith, K. M.; Geldenhuys, W. J.; Feng, Y.; Pink, J. J.; Dowlati, A.; Xu, Y.; Zhou, A.; Su, B. J. Med. Chem. 2012, 55, 3425.

32. Zhong, B.; Chennamaneni, S.; Lama, R.; Yi, X.; Geldenhuys, W. J.; Pink, J. J.; Dowlati, A.; Xu, Y.; Zhou, A.; Su, B. J. Med. Chem. 2013, 56, 5306. 